\title{
Structural, magnetic and Mössbauer studies on nickel-zinc ferrites synthesized via a precipitation route
}

\author{
S. K. Date ${ }^{* 1}$, P. A. Joy ${ }^{* * 1}$, P. S. Anil Kumar ${ }^{* * 1}$, B. Sahoo ${ }^{2}$, and W. Keune ${ }^{2}$ \\ ' Physical and Materials Chemistry Division, National Chemical Laboratory, Pune 411008, India \\ ${ }^{2}$ Laboratory for Applied Physics, University of Duisburg-Essen, D-47048, Duisburg, Germany
}

PACS 33.45.+x, 75.30.Cr, 75.50.Gg, 75.50.Tt, 75.60.Ej, 82.80.Ej

Polycrystalline Ni-Zn ferrite, with a well-defined composition, $\mathrm{Ni}_{0.8} \mathrm{Zn}_{0.2} \mathrm{Fe}_{2} \mathrm{O}_{4}$, synthesized by a lowtemperature method showed the formation of a cubic ferrite phase with a crystallite size of $\sim 15 \mathrm{~nm}$ and saturation magnetization of $\mathrm{M}_{\mathrm{s}} \approx 44 \mathrm{emu} / \mathrm{g}$ at room temperature. When calcined at higher temperatures (up to $1200{ }^{\circ} \mathrm{C}$ ) the magnetization increased continuously to $\mathrm{M}_{\mathrm{s}} \approx 67 \mathrm{emu} / \mathrm{g}$. To understand the magnetic nature of the cubic ferrite phase formed at a temperature as low as $80{ }^{\circ} \mathrm{C},{ }^{57} \mathrm{Fe}$ Mössbauer spectra were recorded for samples annealed at three different temperatures, without any external magnetic field, and with an external field of $\mathrm{H}_{\mathrm{ext}}=5 \mathrm{~T}$, at $4.2 \mathrm{~K}$. The spectral parameters at room temperature, namely, isomer shift, quadrupole splitting and hyperfine field, confirmed the presence of ultrafine superparamagnetic crystallites of Ni-Zn ferrite. The Mössbauer spectra at $4.2 \mathrm{~K}$ revealed spin relaxation effects resulting in very broad sextets, characteristic of ultrafine crystallites. The Mössbauer spectra recorded at $4.2 \mathrm{~K}$ and $\mathrm{H}_{\mathrm{ext}}=5 \mathrm{~T}$ showed well-resolved two-sextet pattern with characteristic hyperfine interaction parameters of the cubic ferrite phase.

\section{Introduction}

Nickel-zinc ferrite is a soft magnetic material having low magnetic coercivity and high resistivity values. The high electrical resistivity and excellent magnetic properties make this ferrite an automatic choice as a core material for power transformers in electronic and telecommunication applications in megahertz frequency regions $[1,2]$. This ferrite is commonly produced by the conventional ceramic process, which involves high-temperature solid-state reaction between constituent oxide/carbonates. However, the method has some inherent drawbacks such as i) poor compositional control, ii) chemical inhomogeneity, iii) coarser particle size, iv) introduction of impurities during ball-milling/grinding and v) energyintensive. In addition, the coarser and non-uniform particles, on compacting, results in the formation of voids or low-density areas in green compacts. On sintering, one ends up with non-reproducible products in terms of their magnetic performance parameters (rejection ratio is high). Wet chemical methods are being pursued to overcome these drawbacks and to produce ultra-fine, homogeneous and reproducible ferrite powders using aqueous solutions of salts of constituent ions [3-8]. Recently, microwavehydrothermal synthesis of nano phase ferrites has been reported in the literature $[9,10]$. In this paper, we report the magnetic properties and Mössbauer spectral studies of a Ni-Zn ferrite synthesized by a co-

\footnotetext{
"Now at Department of Physics, University of Pune, Pune 411007, India.

** Corresponding author: e-mail: joy@dalton.ncl.res.in, Phone: +91 202589 3300, Fax: +91 2025893044

${ }_{* * *}^{*}$ Now at Department of Physics, Indian Institute of Science, Bangalore 560012, India.
} 


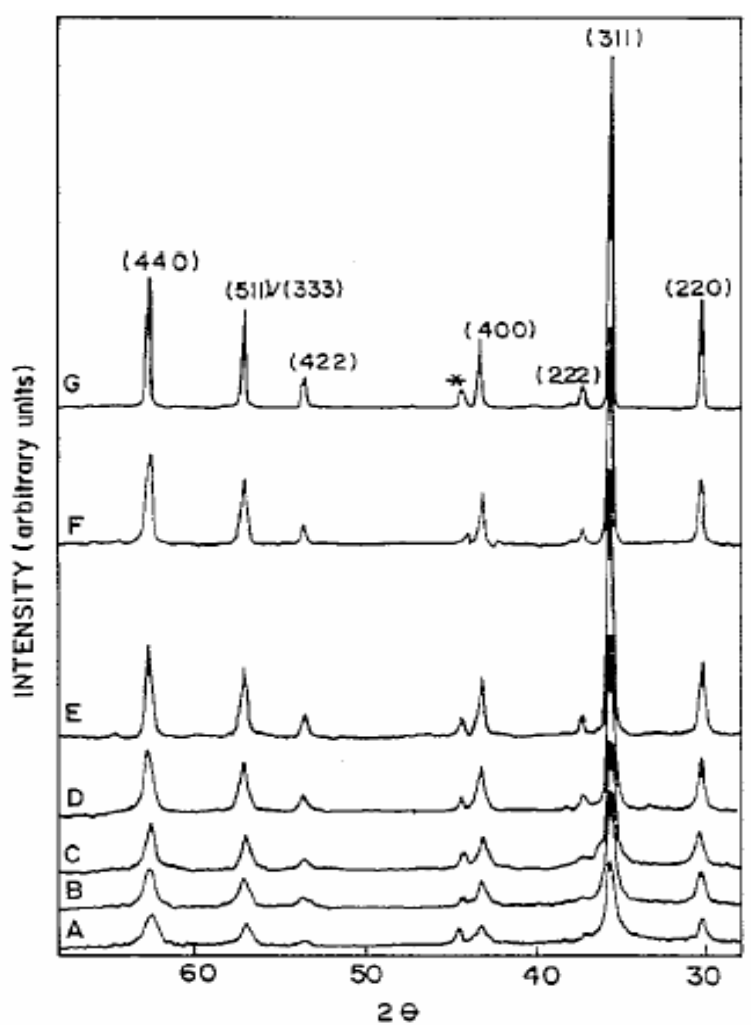

Fig. 1 Powder XRD patterns of the as-dried sample (A) and after calcining at 200 (B), 400 (C), 600 (D), 800 (E), 1000 (F), and $1200{ }^{\circ} \mathrm{C}$ (G). The peak marked $\left(^{*}\right)$ is from the sample holder.

precipitation method at low temperatures. The chemically synthesized precursors produce ferrite powders at relatively low temperatures $\left(\leq 600{ }^{\circ} \mathrm{C}\right)$ with greater reactivity and sinterability.

\section{Experimental}

Details of the synthesis procedures are discussed elsewhere in the literature [4-6]. A precipitate obtained from the co-precipitation technique was dried in air at $80{ }^{\circ} \mathrm{C}$ in an electrically heated oven. The ferrite powder thus obtained (sample A) was divided into six equal parts for calcination at higher temperatures. The calcinations were carried out at six different temperatures from 200 to $1200{ }^{\circ} \mathrm{C}$ at an interval of 200 ${ }^{\circ} \mathrm{C}$ and these calcined samples (designated as B-G) were used to study the effect of calcination temperature on the evolution of micro-structurally homogeneous single-phase ferrites and the related magnetic properties. The different samples were characterized by powder X-ray diffraction (XRD) using a Philips PW 1730 diffractometer with $\mathrm{Cu}-\mathrm{K}_{\alpha}$ radiation with Nickel filter $(\lambda=1.5428 \AA)$, SEM using a Leica Cambridge 440 microscope, magnetic measurements, with variable temperatures and applied magnetic fields ( $80 \mathrm{~K} \leq \mathrm{T} \leq 873 \mathrm{~K}, 0-15 \mathrm{kOe}$ ), using a EG \& G PAR model 4500 vibrating sample magnetometer and ${ }^{57} \mathrm{Fe}$-transmission Mössbauer spectroscopy at variable temperatures and applied magnetic field (4.2$300 \mathrm{~K}, 5 \mathrm{~T}$ ) using a commercial Oxford cryostat. A standard least-square fitting program was used to derive Mössbauer hyperfine interaction parameters.

\section{Results and discussion}

Ni-Zn ferrite is a soft magnetic ceramic material that has the configuration $\left(\mathrm{Zn}_{x} \mathrm{Fe}_{1-x}\right)_{A}\left[\mathrm{Ni}_{1-x} \mathrm{Fe}_{1+x}\right]_{B} \mathrm{O}_{4}$, where the subscripts $A$ and $B$ denote tetrahedral (A) and octahedral (B) sites in the $\mathrm{AB}_{2} \mathrm{O}_{4}$ spinel structure [1]. Every Fe ion occupying an A site is surrounded by 12 nearest neighbours ( $\mathrm{Ni}$ or Fe ions) at $\mathrm{B}$ sites, and every $\mathrm{Fe}$ ion at the B site is surrounded by 6 nearest neighbours ( $\mathrm{Zn}$ or Fe ions) at the A sites. 
For the hyperfine interaction influencing the Mössbauer spectral lines and their line shapes, we take into our analysis the stronger A-B interactions rather than the A-A or B-B interactions. The different surrounding of a $\mathrm{Fe}$ site leads to a varying hyperfine field at each iron nucleus depending on the number of nearest Fe or Ni neighbours (A site) and Fe or Zn neighbours (B site).

The powder XRD patterns of the as-dried powder (A) and the samples calcined at different temperatures (B to $G$ ) are shown in Fig. 1. It is evident from the XRD pattern of sample A that a pure singlephase spinel is formed, as all the peaks match well with the characteristic reflections of Ni- $\mathrm{Zn}$ ferrite. The peaks are broad indicating the fine crystallite nature $(\approx 16 \mathrm{~nm})$ of the ferrite formed. For the calcined samples (B to $\mathrm{G}$ ) also all the characteristics reflections of $\mathrm{Ni}-\mathrm{Zn}$ ferrites are seen with increased intensity and sharpness. It implies progressive growth of crystallites and better crystallinity after calcining at higher temperatures (16-44 $\mathrm{nm})$. This data is also supported by SEM studies on all samples.

The M-H curves of the different samples (A-G) are shown in Fig. 2. The ferrite formed at $80{ }^{\circ} \mathrm{C}$ (sample A) shows a continuous increase in the magnetization, and the interesting observation is that the 16 $\mathrm{nm}$ crystallites attained the magnetization of $40 \mathrm{emu} / \mathrm{g}$ at an applied field of $5 \mathrm{kOe}$. The other samples have attained much higher magnetization values at $5 \mathrm{kOe}$ field, confirming the evolution of atomically and microstructurally well-defined ferrimagnetic phase at higher calcination temperatures. The maximum $\sigma_{\mathrm{s}}$ value obtained is $96 \%$ of the reported value for this composition. Curie temperature $\left(\mathrm{T}_{\mathrm{c}}\right)$ is obtained as $480{ }^{\circ} \mathrm{C}$, comparable to the literature value for this composition.

Figure 3 shows the ${ }^{57} \mathrm{Fe}$ Mössbauer spectra of samples A and G, recorded at 300 and $4.2 \mathrm{~K}$, as well as in the presence of an applied magnetic field of $5 \mathrm{~T}$, at $4.2 \mathrm{~K}$, in the direction parallel to the $\gamma$-rays. The Mössbauer spectrum of $\mathrm{A}$ at $300 \mathrm{~K}$ shows a very broad doublet due to the electron spin relaxation effect attributable to the superparamagnetic nature of the $16 \mathrm{~nm}$ ferrite powder. The non-lorentzian nature and the relatively sharp line of the doublet at lower relative velocity indicate a positive $\mathrm{EFG}$ parameter. $\Delta \mathrm{E}_{\mathrm{Q}}$ $=0.58 \mathrm{~mm} / \mathrm{sec}$ and I.S. $=0.19 \mathrm{~mm} / \mathrm{sec}$ agree well with the data reported in the literature [3] indicating the presence of $\mathrm{Fe}^{3+}$ ions situated in distorted local lattice environments. The random distribution of near neighbours of ferric ions at $\mathrm{A}$ and $\mathrm{B}$ sites supports the broad nature of the quadrupole doublet. The Mössbauer spectrum at $4.2 \mathrm{~K}$ in zero applied field shows a broad sextet pattern indicating the slowing down of the spin relaxation effects of the superfine crystallites. The broad spectrum was fitted with hyperfine field distribution programme and the derived Mössbauer parameters are in agreement with the data reported earlier [3]. The Mössbauer spectrum at $4.2 \mathrm{~K}$ in presence of applied magnetic field of $5 \mathrm{~T}$ clearly indicates further slowing down of spin relaxation effects resulting in sharp resolved sub-spectra characteristics of $\mathrm{Fe}^{3+}$ ions at $\mathrm{A}$ and $\mathrm{B}$ sites in ferrites [11]. It also shows the effect of $\mathrm{H}_{\text {app }}$ on inner lines of the sextet $\left(\Delta \mathrm{m}_{\mathrm{I}}=0\right)$. The Mössbauer spectra for the sample calcined at $1200{ }^{\circ} \mathrm{C}$, shown in Fig. 3 , are recorded in the identical way and the derived Mössbauer parameters confirmed the formation of homogenous single phase Ni-Zn ferrite.

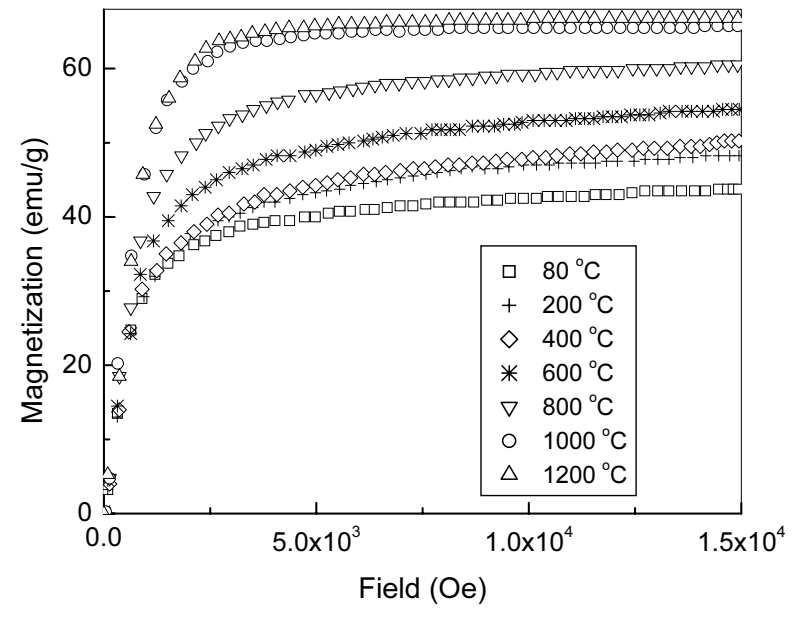

Fig. $2 \mathrm{M}$ versus $\mathrm{H}$ behaviour (at room temperature) of the as-dried sample and those calcined at different temperatures, as indicated. 

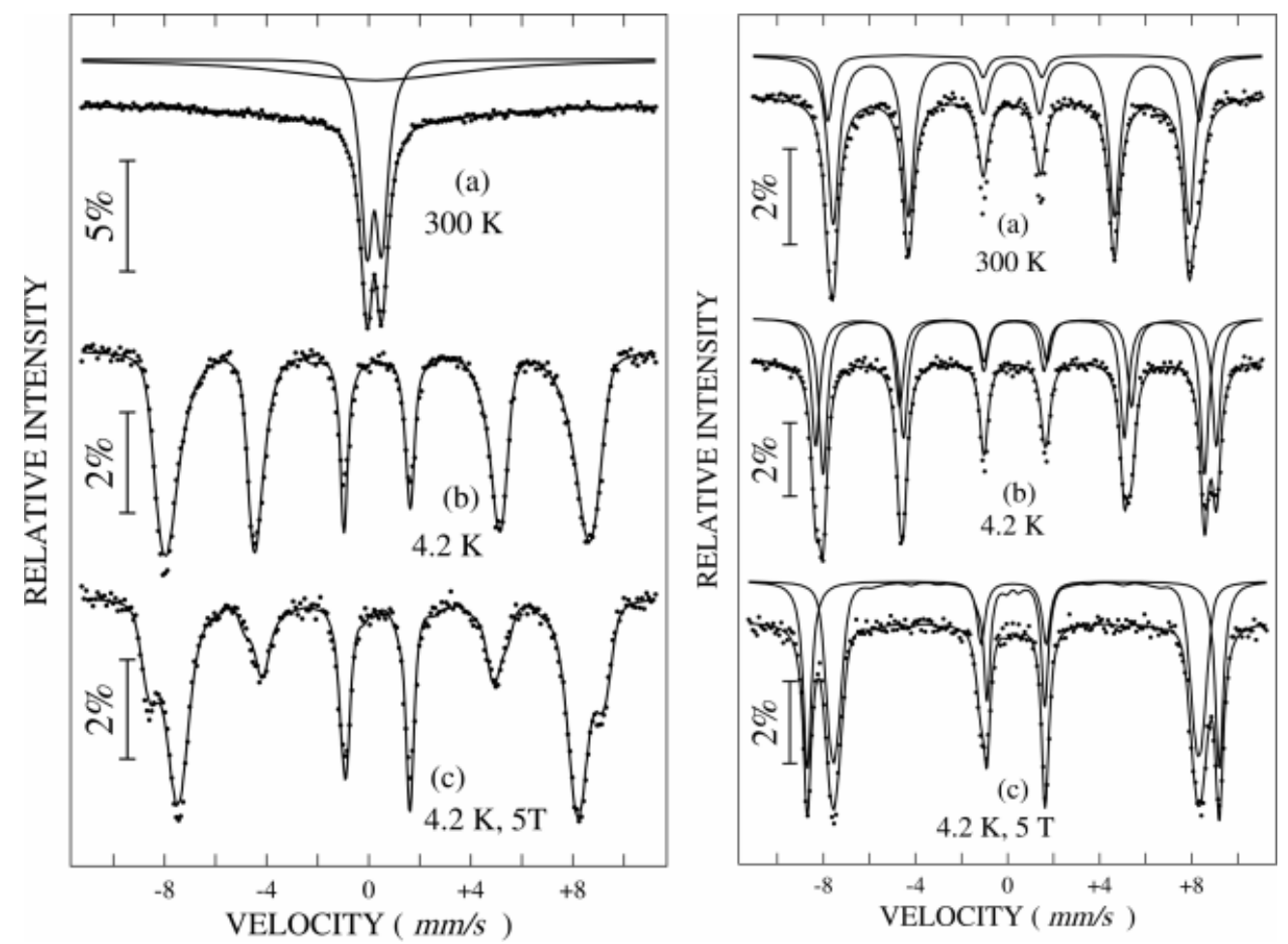

Fig. 3 Mössbauer spectra of samples A (left) and G (right) recorded at (a) $300 \mathrm{~K}$, (b) $4.2 \mathrm{~K}$, and (c) $4.2 \mathrm{~K}$ in a magnetic field of $5 \mathrm{~T}$.

In conclusion, powder XRD, SEM, VSM and Mössbauer data indicated clearly the formation of ultrafine single phase of Ni-Zn ferrite at low temperatures. Additionally, experimental work via microwavehydrothermal route for synthesizing the nanoferrites is in progress.

Acknowledgements One of us (SKD) wishes to thank Alexander Von Humboldt Foundation for extending the financial support to carry out low temperature/high field Mössbauer measurements. Special thanks are due to Duisburg Mössbauer Group for all the necessary technical support.

\section{References}

[1] A. Goldman, Modern Ferrite Technology (Van Nostrand Reinhold, New York, 1990), p. 145.

[2] P. I. Slick, in: Ferromagnetic Materials, Vol. 2, E. P. Wohlfarth (ed.) (North-Holland, Amsterdam, 1980), p.196.

[3] A.. S. Albuquerque, J. D. Ardisson, W. A. A. Macedo, and M. C. M. Alves, J. Appl. Phys. 87, 4352 (2000).

[4] P. S. A. Kumar, J. J. Shrotri, S. D. Kulkarni, C. E. Deshpande, and S. K. Date, Mater. Lett. 27, 293 (1996).

[5] P. S. A. Kumar, S. R. Sainkar, J. J. Shrotri, C. E. Deshpande, and S. K. Date, in: Proceedings of 8th International Conference on Ferrites (ICF-8), Kyoto/Tokyo, Japan, 2000, pp. 579-581.

[6] P. S. A. Kumar, J. J. Shrotri, C. E. Deshpande, and S. K. Date, J. Appl. Phys. 81, 4788 (1997).

[7] C. Liu, B. Zou, A. J. Rondinone, and Z. J. Zhang, J. Phys. Chem. B 104, 1141 (2000).

[8] P. S. A. Kumar, Ph.D. Thesis, University of Pune, 1998.

[9] S. Komarneni, M. C. D’Arrigo, C. Leonelli, G. C. Pellacani, and H. Katsuki, J. Am. Ceram. Soc. 81, 3041 (1998).

[10] S. Verma, P. A. Joy, Y. B. Khollam, H. S. Potdar, and S. B. Deshpande, Mater. Lett. 58, 1092 (2004).

[11] R. E. Vandenberghe and E. DeGrave, in: Mössbauer Spectroscopy Applied to Inorganic Chemistry, G. J. Long and F. Grandjean (eds.) (Plenum Press, New York, 1989). 